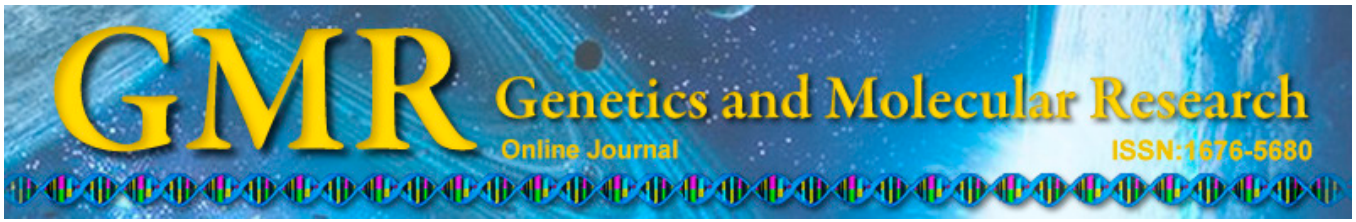

\title{
Relationship between genetic polymorphisms in $M C P-1, C C R-2$, and non-small-cell lung cancer in the Han nationality of Northern China
}

\author{
L. Yang, J. Wang, F.-G. Li, M. Han, X.-J. Chang and Z.-T. Wang \\ Department of Thoracic Surgery, Beijing Chest Hospital, \\ Capital Medical University, Beijing, China \\ Corresponding author: Z.-T. Wang \\ E-mail: wztdoctor@163.com
}

Genet. Mol. Res. 14 (2): 3745-3752 (2015)

Received May 13, 2014

Accepted October 25, 2014

Published April 22, 2015

DOI http://dx.doi.org/10.4238/2015.April.22.2

\begin{abstract}
Lung cancer is a common malignant tumor worldwide and is now the leading cause of cancer-related deaths. Monocyte chemoattractant protein 1 (MCP-1) and its receptor chemokine receptor 2 (CCR-2) are important chemokines. We examined the polymorphisms of 338 unrelated patients with non-small cell lung carcinoma (NSCLC) and 200 unrelated healthy controls of Han nationality in Northern China using polymerase chain reaction-restriction fragment length polymorphism. We found a significant increase in the frequency of the $M C P-1$ AA genotype $[0.293$ vs 0.195 , odds ratio $(\mathrm{OR})=1.71,95 \%$ confidence interval $(\mathrm{CI})=1.13-2.60]$ and a significant decrease in the frequency of the GG genotype $(0.290$ vs $0.41, \mathrm{OR}=0.64,95 \% \mathrm{CI}=$ $0.47-0.87)$ in NSCLC patients compared to controls. The frequencies of AA-ww $(0.151$ vs $0.090, \mathrm{P}=0.041, \mathrm{OR}=1.80,95 \% \mathrm{CI}=1.33-2.43)$ and AA-wm $(0.136$ vs $0.080, \mathrm{P}=0.049, \mathrm{OR}=1.81,95 \% \mathrm{CI}=1.01$ $3.27)$ were higher in lung cancer patients than in healthy controls; the frequency of GG-wm $(0.121$ vs $0.190, \mathrm{P}=0.030, \mathrm{OR}=0.60,95 \% \mathrm{CI}$
\end{abstract}


$=0.38-0.95)$ was lower in lung cancer patients than in healthy controls. Based on these results, the polymorphism in $M C P-1$ may be correlated with the development of NSCLC in the Han nationality of Northern China. However, the polymorphism in CCR-2 is not involved in NSCLC.

Key words: Chemokine receptor 2; Monocyte chemoattractant protein 1; Non-small cell lung carcinoma; Polymorphism

\section{INTRODUCTION}

Lung cancer is a common malignant tumor worldwide and has become the leading cause of cancer-related deaths (Youlden et al., 2008). Over the past decade, the morbidity and mortality of lung cancer have markedly increased in China (Yang et al., 2004). There are 2 main types of lung cancer: small-cell lung cancer (SCLC) and non-small-cell lung cancer (NSCLC); NSCLC accounts for approximately $85 \%$ of all cases of lung cancer and shows poor prognosis (Tsitsias et al., 2013). To improve the poor prognosis of patients with NSCLC, the biology of lung cancer, including the effects of chemokines, must be further understood.

Monocyte chemoattractant protein 1 (MCP-1) is an important chemokine and was the third chemokine to be purified to homogeneity after platelet 4 and interleukin-8 (Matsushima et al., 1989). MCP-1 contains 76-amino acid residues, and its gene is located at 17q11:2-q12 (Rollins et al., 1991a). As a chemokine, MCP-1 can be produced by many fibroblasts, keratinocytes, and several cancer cell lines (Arndt et al., 2004; Lee et al., 2004; Mestdagt et al., 2006; Distler et al., 2009). Not only can it stimulate chemotaxis of peripheral blood monocytes and memory $\mathrm{T}$ cells, but it also can induce calcium flux, respiratory burst activity, and adhesion molecule and proinflammatory cytokine expression in monocytes (Rollins et al., 1991b; Jiang et al., 1992; Carr et al., 1994; Charo and Ransohoff, 2006). Thus, MCP-1 may play an important role in the biology of NSCLC. Previous studies showed that MCP-1 is related to macrophage infiltration (Arenberg et al., 2000) and bone metastases in NSCLC (Cai et al., 2009). Chemokine receptor 2 (CCR-2) is a major receptor of MCP-1 that is largely produced by cancer cells and is responsible for recruiting macrophages to tumors such as bladder, cervix, ovary, lung, and breast tumors (Kurihara et al., 1997; MacKay, 2001). The G to A polymorphism at position 190 in the $C C R-2$ gene replaces valine with isoleucine at amino acid 64 (CCR-2 V64I) (Smith et al., 1997). This polymorphism has been shown to be relevant to the susceptibility of some diseases (Manome et al., 1995; Nakayama et al., 2004; Ivansson et al., 2007; Prasad et al., 2007; Lin et al., 2012). A recent study suggested that the polymorphism in the $M C P-1$ distal regulatory region $(-2518 \mathrm{~A} / \mathrm{G})$ may be associated with susceptibility to NSCLC (Yang et al., 2010). As the receptor of MCP-1, the CCR-2 V64I polymorphism may be also relevant to the susceptibility to NSCLC. However, studies of the CCR-2 V64I polymorphism in NSCLC are limited. In addition, there have been no studies of polymorphisms in both genes.

In this study, we examined these polymorphisms in 338 unrelated patients with NSCLC and 200 unrelated healthy controls of Han nationality in Northern China using polymerase chain reaction-restriction fragment length polymorphism (PCR-RFLP). The aim of our study was to investigate the role of polymorphisms $M C P-1-2518 \mathrm{~A} / \mathrm{G}$ and $C C R-2 \mathrm{~V} 64 \mathrm{I}$ in the genetic susceptibility to NSCLC. 


\section{MATERIAL AND METHODS}

\section{Subjects}

The study enrolled 338 unrelated patients with NSCLC of Han nationality from Northern China. All patients were admitted to our hospital between October 2012 and September 2013, and lung cancer was diagnosed histologically. The subjects ranged in age from 35 to 78 years; 167 subjects were male and 171 were female. A total of 152 patients were diagnosed with squamous carcinoma and the other 186 patients were diagnosed with adenocarcinoma. The 200 controls were unrelated healthy people of Han nationality from Northern China, including 106 males and 94 females. All underwent a chest X-ray check and showed no anomalies. This study was approved by our institutional review board. All subjects provided informed consent for this study.

\section{$M C P-1$ and $C C R-2$ genotyping}

Genomic DNA from patients and controls was extracted using standard techniques from peripheral blood leukocytes. The $\mathrm{A}$ to $\mathrm{G}$ polymorphism of $M C P-1$ at position -2518 was identified by PCR and RFLP. We used the EQ5.5-50 EasyDo ${ }^{\mathrm{TM}}$ PCR PreMix system (SBS Genentech Co., Ltd., Beijing, China), which contained 2 U Taq DNA polymerase, $5 \mu \mathrm{L} 10 \mathrm{X}$ PCR buffer, $5 \mu \mathrm{L}$ loading dye, and $5 \mu \mathrm{L}$ stabilizer. To this solution, we added $2 \mu \mathrm{L}$ DNA, $2 \mu \mathrm{L}$ of each forward and reverse primer, and $30 \mu \mathrm{L}$ pure water. The forward primer for $M C P-1$ was 5'-TTCTCTTCTACGGGATCTGGG-3' and the reverse primer was 5'-GTCTCTCCTGGCTTAGTCAT-3'. The forward primer for $C C R-2$ was 5'-ATCAGAAATACCAACGAGAGCGG-3' and the reverse primer was 5'-ACACCGAAGCAGGGTTTTCAGG-3'. PCR was performed under the following cycling condition: $95^{\circ} \mathrm{C}$ for $3 \mathrm{~min}$, followed by $94^{\circ} \mathrm{C}$ for $40 \mathrm{~s}, 59^{\circ} \mathrm{C}$ for $40 \mathrm{~s}$, and $74^{\circ} \mathrm{C}$ for $40 \mathrm{~s}$ for 35 cycles, with a final extension step at $72^{\circ} \mathrm{C}$ for $4 \mathrm{~min}$. Three microliters of PCR product was digested with $2 \mathrm{U} \mathrm{PvuII}$ at $37^{\circ} \mathrm{C}$ for $60 \mathrm{~min}$ in a final volume of $10 \mu \mathrm{L}$ for MCP-1. Three microliters of PCR product was digested with $2 \mathrm{U} \mathrm{BtsCI}$ at $50^{\circ} \mathrm{C}$ for $60 \mathrm{~min}$ in a final volume of $10 \mu \mathrm{L}$ for $C C R-2$. The resulting fragments were separated by electrophoresis on a $3 \%$ agarose gel and were visualized under ultraviolet light after staining with ethidium bromide.

\section{Statistical analysis}

Genotype frequencies were calculated by direct counting. The frequency differences of the genotypes between the different groups were estimated using the chi-square test with SPSS version 13.0 (SPSS, Inc., Chicago, IL, USA). The level of significance was set at $\mathrm{P}<$ 0.05 . If the frequency difference of genotype showed statistical significance, the odds ratio (OR) and 95\% confidence interval (CI) were calculated.

\section{RESULTS}

\section{MCP-1 genotyping}

The PCR products were 466-bp fragments. The PvuII-digested DNA segment from G/G homozygous individuals yielded 2 fragments: 327 and 139 bp; DNA from G/A hetero- 
zygous individuals yielded 3 fragments: 466, 327, and 139 bp; DNA from A/A homozygous individuals yielded only 1 fragment: 466 bp (Figure 1).

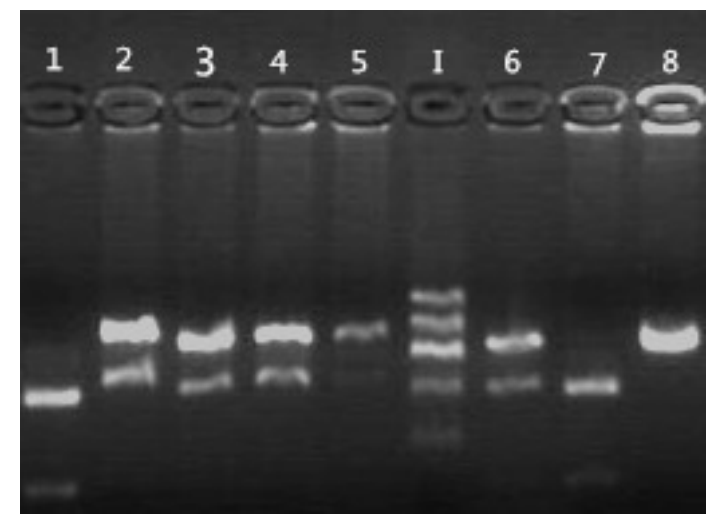

Figure 1. Three genotypes separated by electrophoresis. Lanes 2,3, 4, and $6=\mathrm{AG}$ genotype; lanes 1 and $7=\mathrm{GG}$ genotype; lanes 5 and $8=$ AA genotype; lane $I=100$-bp DNA marker.

\section{CCR-2 genotyping}

The PCR products were 669-bp fragments. The PvuII-digested DNA segment from wild-type homozygous (w/w) individuals yielded 3 fragments: 102, 203, and 364 bp; DNA from heterozygous (w/m) individuals yielded 4 fragments: 102, 160, 203, and 364 bp; DNA from mutation-type homozygous $(\mathrm{m} / \mathrm{m}$ ) individuals yielded 3 fragments: 102, 160, and 203 bp (Figure 2).

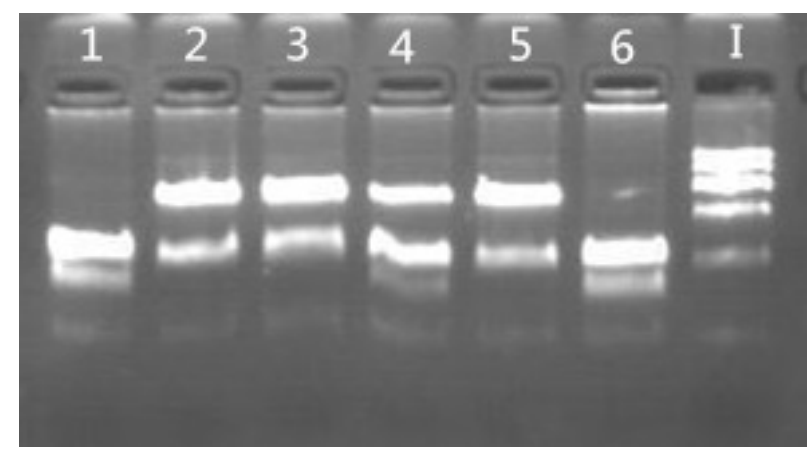

Figure 2. Three genotypes separated by electrophoresis. Lanes 2,3 , and $5=\mathrm{w} / \mathrm{w}$ genotype; lane $4=\mathrm{w} / \mathrm{m}$ genotype; lanes 1 and $6=\mathrm{m} / \mathrm{m}$ genotype; lane $I=100$-bp DNA marker.

\section{Genotypes of MCP-1 and CCR-2 in NSCLC patients}

The distributions of the AA, AG, and GG genotypes of $M C P-1$ as well as the distributions of the ww, wm, and $\mathrm{mm}$ genotypes of $C C R-2$ are shown in Table 1 . There was a significant increase in the frequency of the AA genotype $(0.293 v s 0.195, \mathrm{OR}=1.71,95 \% \mathrm{CI}=1.13-2.60)$ and a significant decrease in the frequency of the GG genotype $(0.290$ vs $0.41, \mathrm{OR}=0.64,95 \% \mathrm{CI}$ $=0.47-0.87$ ) in NSCLC patients compared to controls. The frequencies of the ww, wm, and $\mathrm{mm}$ genotypes of CCR-2 showed no difference between NSCLC patients and controls (Table 1). 
Table 1. Comparison of the distribution of genotypes in non-small-cell lung cancer (NSCLC) patients and controls.

\begin{tabular}{|c|c|c|c|c|c|}
\hline & Squamous carcinoma & Adenocarcinoma & $\chi^{2}$ & $\mathrm{P}$ & OR $(95 \% \mathrm{CI})$ \\
\hline AA & $0.293(99 / 338)$ & $0.195(39 / 200)$ & 6.315 & 0.012 & $1.71(1.13-2.60)$ \\
\hline $\mathrm{AG}$ & $0.417(141 / 338)$ & $0.395(79 / 200)$ & 0.255 & 0.613 & \\
\hline GG & $0.290(98 / 338)$ & $0.410(82 / 200)$ & 8.135 & 0.004 & $0.64(0.47-0.87)$ \\
\hline $\mathrm{mm}$ & $0.041(14 / 338)$ & $0.065(13 / 200)$ & 1.446 & 0.226 & \\
\hline $\mathrm{mw}$ & $0.414(140 / 338)$ & $0.430(86 / 200)$ & 0.129 & 0.720 & \\
\hline ww & $0.545(184 / 338)$ & $0.505(101 / 200)$ & 0.782 & 0.376 & \\
\hline
\end{tabular}

\section{Genotypes of $M C P-1$ and $C C R-2$ in patients with squamous carcinoma and adenocarcinoma}

Among the NSCLC patients, 152 patients were diagnosed with squamous carcinoma and 186 with adenocarcinoma. The frequencies of AA, AG, GG in $M C P-1$ and ww, wm, mm in CCR-2 are shown in Table 2. The difference of the genotypes in patients with squamous carcinoma and adenocarcinoma was not statistically significant.

Table 2. Comparison of the distribution of genotypes in squamous carcinoma and adenocarcinoma.

\begin{tabular}{|c|c|c|c|c|}
\hline & Squamous carcinoma & Adenocarcinoma & $\chi^{2}$ & $\mathrm{P}$ \\
\hline AA & $0.289(44 / 152)$ & $0.296(55 / 186)$ & 0.016 & 0.900 \\
\hline AG & $0.435(66 / 152)$ & $0.403(75 / 186)$ & 0.330 & 0.565 \\
\hline GG & $0.276(42 / 152)$ & $0.301(56 / 186)$ & 0.249 & 0.618 \\
\hline $\mathrm{mm}$ & $0.039(6 / 152)$ & $0.043(8 / 186)$ & 0.026 & 0.871 \\
\hline $\mathrm{mw}$ & $0.428(65 / 152)$ & $0.403(75 / 186)$ & 0.205 & 0.650 \\
\hline wW & $0.533(81 / 152)$ & $0.554(103 / 186)$ & 0.147 & 0.702 \\
\hline
\end{tabular}

\section{Comparison of different combinations of $M C P-1$ and $C C R-2$ genotypes in patients with NSCLC and controls}

Table 3 shows the frequencies of different combinations of $M C P-1$ and $C C R-2$ genotypes in patients with NSCLC and healthy controls. We found that the frequencies of combinations were higher in lung cancer patients than in healthy controls: AA-ww $(0.151$ vs $0.090, \mathrm{P}=$ $0.041, \mathrm{OR}=1.80,95 \% \mathrm{CI}=1.33-2.43), \mathrm{AA}-\mathrm{wm}(0.136$ vs $0.080, \mathrm{P}=0.049, \mathrm{OR}=1.81,95 \% \mathrm{CI}$ $=1.01-3.27)$. The frequency of GG-wm was lower in lung cancer patients than in healthy controls. The frequencies in lung cancer patients and healthy controls were 0.121 and 0.190 , respectively $(\mathrm{P}=0.030, \mathrm{OR}=0.60,95 \% \mathrm{CI}=0.38-0.95)$.

Table 3. Different combinations of $M C P-1$ and $C C R-2$ genotypes in patients with NSCLC and controls.

\begin{tabular}{|c|c|c|c|c|c|}
\hline Genotype & NSCLC & Control & $\chi^{2}$ & $\mathrm{P}$ & OR $(95 \% \mathrm{CI})$ \\
\hline AA-mm & $0.006(2 / 338)$ & $0.025(5 / 200)$ & 3.563 & 0.108 & \\
\hline AG-mm & $0.024(8 / 338)$ & $0.010(2 / 200)$ & 1.287 & 0.336 & \\
\hline GG-mm & $0.012(4 / 338)$ & $0.030(6 / 200)$ & 2.273 & 0.185 & \\
\hline AA-ww & $0.151(51 / 338)$ & $0.090(18 / 200)$ & 4.166 & 0.041 & $1.80(1.33-2.43)$ \\
\hline AG-ww & $0.236(80 / 338)$ & $0.225(45 / 200)$ & 0.096 & 0.833 & \\
\hline GG-ww & $0.157(53 / 338)$ & $0.190(38 / 200)$ & 0.985 & 0.342 & \\
\hline AA-wm & $0.136(46 / 338)$ & $0.080(16 / 200)$ & 3.878 & 0.049 & $1.81(1.01-3.27)$ \\
\hline AG-wm & $0.157(53 / 338)$ & $0.160(32 / 200)$ & 0.10 & 0.922 & \\
\hline GG-wm & $0.121(41 / 338)$ & $0.190(38 / 200)$ & 4.733 & 0.030 & $0.60(0.38-0.95)$ \\
\hline
\end{tabular}




\section{Comparison of different combinations of $M C P-1$ and $C C R-2$ genotypes in patients with squamous carcinoma and adenocarcinoma}

Table 4 shows the frequencies of different combinations of $M C P-1$ and $C C R-2$ genotypes in patients with squamous carcinoma and adenocarcinoma. We found that the frequencies showed no difference between patients with squamous carcinoma and those with adenocarcinoma.

$\begin{aligned} & \text { Table 4. Different combinations of } M C P-1 \text { and } C C R-2 \\
& \text { adenocarcinoma. }\end{aligned}$
\begin{tabular}{lcccc}
\hline & Senotypes in patients with squamous carcinoma and \\
\hline AA-mm & $(0 / 152)$ & Adenocarcinoma & $\chi^{2}$ & $P$ \\
AG-mm & $(5 / 152)$ & $(2 / 186)$ & 1.644 & 0.504 \\
GG-mm & $(1 / 152)$ & $(3 / 186)$ & 1.017 & 0.475 \\
AA-ww & $(6 / 152)$ & $(3 / 186)$ & 0.652 & 0.630 \\
AG-ww & $(34 / 152)$ & $(25 / 186)$ & 0.877 & 0.349 \\
GG-ww & $(21 / 152)$ & $(46 / 186)$ & 0.258 & 0.611 \\
AA-wm & $(8 / 152)$ & $(32 / 186)$ & 0.726 & 0.394 \\
AG-wm & $(27 / 152)$ & $(26 / 186)$ & 0.734 & 0.392 \\
GG-wm & $(20 / 152)$ & $(21 / 186)$ & 0.906 & 0.361 \\
\hline
\end{tabular}

\section{DISCUSSION}

As a potent chemokine, the influence of MCP-1 on monocytes and macrophages indicates its important role in tumor immunity. MCP-1 has been shown to suppress tumor growth both in T lymphocyte-independent and lymphocyte-dependent manners, where the effect is notably dose-dependent. The polymorphism in the $M C P-1$ distal regulatory region (-2518A/ G) may affect the transcriptional activity and level of MCP-1 expression. Thus, the $M C P-1$ polymorphism may affect tumor immunity and result in inconsistencies in tumor susceptibility by influencing MCP-1 production. Our previous study showed that the frequency of the $M C P$ 1 AA genotype was higher in NSCLC patients than in controls $(\mathrm{P}=0.003, \mathrm{OR}=3.318,95 \% \mathrm{CI}$ $=1.480-6.652$ ), and the frequency of the GG genotype was lower in NSCLC patients than in controls $(\mathrm{P}=0.032, \mathrm{OR}=0.516,95 \% \mathrm{CI}=0.282-0.944)$. The results of the present study showed that the frequency of the AA genotype was higher in NSCLC patients than in controls $(0.293$ vs $0.195, \mathrm{OR}=1.71,95 \% \mathrm{CI}=1.13-2.60)$, and the frequency of the GG genotype was lower in NSCLC patients than in controls $(0.290$ vs $0.41, \mathrm{OR}=0.64,95 \% \mathrm{CI}=0.47-0.87)$. This result was similar to our previous results suggesting that the polymorphism in $M C P-1$ influences the susceptibility to NSCLC.

CCR-2 is the receptor of MCP-1 and is expressed on monocytes, basophils, activated T-cells, dendritic cells, and natural killer cells. There are 2 transcribed isoforms of CCR-2, including CCR-2A and CCR-2B. The CCR-2 V64I polymorphism leads to enhanced gene expression of the $C C R-2 A$ isoform but no change in $C C R-2 B$ expression. The CCR-2A and CCR-2B isoforms have different functions; CCR-2B can provoke more inflammatory cells than CCR-2A (Wu et al., 2013). Thus, we hypothesized that the CCR-2 V64I polymorphism may be associated with the susceptibility to cancer. Previous studies have reported conflicting results regarding the $C C R-2$ polymorphism and the susceptibility to cervical cancer (Ivansson et al., 2007; Wu et al., 2013). However, there have been no reports examining the effect of the 
$C C R-2$ polymorphism and the susceptibility to NSCLC. Our results suggested that the $C C R-2$ polymorphism was not related to the susceptibility of NSCLC. Moreover, we examined different genotype combinations in $M C P-1$ and $C C R-2$ in NSCLC patients and controls. The results showed that the frequencies of AA-ww $(0.151$ vs $0.090, \mathrm{P}=0.041, \mathrm{OR}=1.80,95 \% \mathrm{CI}=1.33$ $2.43)$ and $\mathrm{AA}-\mathrm{wm}(0.136$ vs $0.080, \mathrm{P}=0.049, \mathrm{OR}=1.81,95 \% \mathrm{CI}=1.01-3.27)$ were higher in lung cancer patients than in healthy controls; the frequency of GG-wm $(0.121$ vs $0.190, \mathrm{P}$ $=0.030, \mathrm{OR}=0.60,95 \% \mathrm{CI}=0.38-0.95)$ was lower in lung cancer patients than in healthy controls. The significance of this observation is unclear because of the negative relationship between the polymorphism of $C C R-2$ and susceptibility to NSCLC.

Squamous carcinoma and adenocarcinoma are both categorized as NSCLC. We examined the genotypes of $M C P-1$ and $C C R-2$ in squamous carcinoma and adenocarcinoma patients and found no difference between the 2 groups.

\section{CONCLUSIONS}

The MCP-1 polymorphism may be correlated with the development of NSCLC in the Han nationality of Northern China. However, the polymorphism in the MCP-1 receptor, CCR-2, was not implicated in NSCLC. The effect of this genotype on NSCLC must be confirmed by a large-scale cross-sectional prospective study to clarify the mechanism of NSCLC development.

\section{ACKNOWLEDGMENTS}

We would like to acknowledge and thank our colleagues in the medical record department for their support and help.

\section{REFERENCES}

Arenberg DA, Keane MP, DiGiovine B, Kunkel SL, et al. (2000). Macrophage infiltration in human non-small-cell lung cancer: the role of CC chemokines. Cancer Immunol. Immunother. 49: 63-70.

Arndt PG, Suzuki N, Avdi NJ, Malcolm KC, et al. (2004). Lipopolysaccharide-induced c-Jun $\mathrm{NH}_{2}$-terminal kinase activation in human neutrophils: role of phosphatidylinositol 3-kinase and Syk-mediated pathways. J. Biol. Chem. 279: 10883-10891.

Cai Z, Chen Q, Chen J, Lu Y, et al. (2009). Monocyte chemotactic protein 1 promotes lung cancer-induced bone resorptive lesions in vivo. Neoplasia 11: 228-236.

Carr MW, Roth SJ, Luther E, Rose SS, et al. (1994). Monocyte chemoattractant protein 1 acts as a T-lymphocyte chemoattractant. Proc. Natl. Acad. Sci. U. S. A. 91: 3652-3656.

Charo IF and Ransohoff RM (2006). The many roles of chemokines and chemokine receptors in inflammation. N. Engl. J. Med. 354: 610-621.

Distler JH, Akhmetshina A, Schett G and Distler O (2009). Monocyte chemoattractant proteins in the pathogenesis of systemic sclerosis. Rheumatology 48: 98-103.

Ivansson EL, Gustavsson IM, Magnusson JJ, Steiner LL, et al. (2007). Variants of chemokine receptor 2 and interleukin 4 receptor, but not interleukin 10 or Fas ligand, increase risk of cervical cancer. Int. J. Cancer 121: 2451-2457.

Jiang Y, Beller DI, Frendl G and Graves DT (1992). Monocyte chemoattractant protein-1 regulates adhesion molecule expression and cytokine production in human monocytes. J. Immunol. 148: 2423-2428.

Kurihara T, Warr G, Loy J and Bravo R (1997). Defects in macrophage recruitment and host defense in mice lacking the CCR2 chemokine receptor. J. Exp. Med. 186: 1757-1762.

Lee YW, Eum SY, Chen KC, Hennig B, et al. (2004). Gene expression profile in interleukin-4-stimulated human vascular endothelial cells. Mol. Med. 10: 19-27. 
Lin HL, Ueng KC, Hsieh YS, Chiang WL, et al. (2012). Impact of MCP-1 and CCR-2 gene polymorphisms on coronary artery disease susceptibility. Mol. Biol. Rep. 39: 9023-9030.

MacKay CR (2001). Chemokines: immunology's high impact factors. Nat. Immunol. 2: 95-101.

Manome Y, Wen PY, Hershowitz A, Tanaka T, et al. (1995). Monocyte chemoattractant protein-1 (MCP-1) gene transduction: an effective tumor vaccine strategy for non-intracranial tumors. Cancer Immunol. Immunother. 41: 227-235.

Matsushima K, Larsen CG, DuBois GC and Oppenheim JJ (1989). Purification and characterization of a novel monocyte chemotactic and activating factor produced by a human myelomonocytic cell line. J. Exp. Med. 169: 1485-1490.

Mestdagt M, Polette M, Buttice G, Noël A, et al. (2006). Transactivation of MCP-1/CCL2 by beta-catenin/TCF-4 in human breast cancer cells. Int. J. Cancer 118: 35-42.

Nakayama EE, Tanaka Y, Nagai Y, Iwamoto A, et al. (2004). A CCR2-V64I polymorphism affects stability of CCR2A isoform. AIDS 18: 729-738.

Prasad P, Tiwari AK, Kumar KM, Ammini AC, et al. (2007). Association of TGF $\beta 1$, TNF $\alpha$, CCR2 and CCR5 gene polymorphisms in type-2 diabetes and renal insufficiency among Asian Indians. BMC Med. Genet. 12: 20.

Rollins BJ, Morton CC, Ledbetter DH, Eddy RL, et al. (1991a). Assignment of the human small inducible cytokine A2 gene, SCYA2 (encoding JE or MCP-1), to 17q11.2-12: evolutionary relatedness of cytokines clustered at the same locus. Genomics 10: 489-492.

Rollins BJ, Walz A and Baggiolini M (1991b). Recombinant human MCP-1/JE induces chemotaxis, calcium flux, and the respiratory burst in human monocytes. Blood 78: 1112-1116.

Smith MW, Carrington M, Winkler C, Lomb D, et al. (1997). CCR2 chemokine receptor and AIDS progression. Nat. Med. 3: 1052-1053.

Tsitsias T, Boulemden A, Ang K, Nakas A, et al. (2013). The N2 paradox: similar outcomes of pre- and postoperatively identified single-zone N2a positive non-small-cell lung cancer. Eur. J. Cardiothorac. Surg. 45: 882-887.

Wu HH, Lee TH, Tee YT, Chen SC, et al. (2013). Relationships of single nucleotide polymorphisms of monocyte chemoattractant protein 1 and chemokine receptor 2 with susceptibility and clinicopathologic characteristics of neoplasia of uterine cervix in Taiwan women. Reprod. Sci. 20: 1175-1183.

Yang L, Parkin DM, Li LD, Chen YD, et al. (2004). Estimation and projection of the national profile of cancer mortality in China: 1991-2005. Br. J. Cancer 90: 2157-2166.

Yang L, Shi GL, Song CX and Xu SF (2010). Relationship between genetic polymorphism of MCP-1 and non-small-cell lung cancer in the Han nationality of North China. Genet. Mol. Res. 9: 765-771.

Youlden DR, Cramb SM and Baade PD (2008). The international epidemiology of lung cancer: geographical distribution and secular trends. J. Thorac. Oncol. 3: 819-831. 